\title{
Evaluation of the Effect of Ecological Migration on Rural Household Development Capability*
}

\author{
Guotao Yang, Zihe Liu, Huijie Zhou \\ School of Economics and Management, Ningxia University, Yinchuan, China \\ Email: mashengya216@163.com
}

Received 10 February 2015; accepted 3 March 2015; published 3 March 2015

Copyright @ 2015 by authors and Scientific Research Publishing Inc.

This work is licensed under the Creative Commons Attribution International License (CC BY). http://creativecommons.org/licenses/by/4.0/

(c) (i) Open Access

\section{Abstract}

This paper aims at evaluating rural household development capability in the procedure of ecological migration in Ningxia with fuzzy mathematics method. To achieve this goal, an indicator system of rural household development capability, which consists of 3 first-class indicators, 21 secondclass indicators and 57 third-class indicators, is established. The data applied in this research are acquired from a field investigation to Liupanshan poverty-ridden areas in Ningxia. According to the results, rural household development capability of resettlement areas has increased compared with that of montanic areas, as is reflected in the three first-class indicators, self development capability, self development awareness and public atmosphere. However, at the same time, a few second- and third-class indicators have decreased owing to migration, such as per capita net income, guanxi network and money-raising ability, etc. This offers an overall view of the changes in peasants' life, and accordingly a few suggestions on future implementation of the migration policy.

\section{Keywords}

Ecological Migration, Rural Household Development Capability, Fuzzy Mathematics Method

\section{Introduction}

Ever since reform and opening up, China has carried out a series of well-organized, well-planned and wide-

*Project in Foundation: NSFC (71263042), Evaluation of Farmer Development Capability in Poverty-Ridden Areas in Liupanshan. Guotao Yang, Ph.D. in management, professor of Ningxia University, and doctoral supervisor: Lingjie Meng, main direction of studying: income inequality; poverty. Zihe Liu (corresponding author), B.A. in management, postgraduate student in Ningxia University, main direction of studying: income inequality. Huijie Zhou, B.A. in economics, postgraduate student in Ningxia University, main direction of studying: income inequality.

How to cite this paper: Yang, G.T., Liu, Z.H. and Zhou, H.J. (2015) Evaluation of the Effect of Ecological Migration on Rural Household Development Capability. Journal of Human Resource and Sustainability Studies, 3, 9-20. 
spread poverty alleviation programs, and has achieved great success. However, in the meantime, there are still challenges and difficulties along the way of alleviation. According to Human Development Report (2013) ${ }^{1}$, from 1990 to 2008, a total of 510 million Chinese have rid themselves of poverty. The experience in this period shows that the obstacles include the large quantity of poverty objectives, the sharp conflict in specific poverty condition, the risk of being poor again (for those who have been alleviated) and the increase of comparative poverty owing to income gap widening. As is said in the National Program for Rural Poverty Alleviation (2011-2020) ${ }^{2}$, Liupanshan in Ningxia Hui Autonomous Region and 10 other poverty-ridden areas have been taken as main battlefield for poverty alleviation. The new tasks in this new era are enhancing the achievements in providing shelter and food, fastening the speed of peasants' ridding of poverty, ameliorating local ecological environment, improving peasants' development capability and diminishing the development disparity. The new tasks see improving peasants' development capability as a fundamental way to resolve poverty issues since only by such means can peasants rid themselves of poverty by their own ability. Therefore, it becomes essential to study rural household development capability in poverty-ridden areas.

Amatya Sen, an Indian economist, studied people's development capability in the round based on his capability approach. In the 1980s, Sen brought up a framework of capability approach, which assessed one's living standard according to his abilities to achieve certain living conditions. These said that abilities were addressed by Sen as capability, and the certain living conditions as combination of functional activities [1]. In his book, Sen pointed out that the functional activities represented all aspects of one's living condition, while capability, a concept of substantial freedom, presented the ability to achieve all kinds of functional activities. Freedom stands for capability that enables people to enjoy the life they find reasonable to value (without special explanation, the concept of freedom used in this paper refers to this substantial freedom), which includes avoiding poverty and hardships such as starvation, disease, premature death and inability to read or calculate [2]. Accordingly, the living condition one experiences is directly related to his chances of choosing, or in other words, his capability.

On evaluation of rural household development capability, researches of academics at home can be sorted into two kinds, descriptive evaluation and indicative evaluation. Descriptive evaluation usually estimates the factors of rural household development capability with statistical description. What makes different analysis dissimilar is their emphasis. Some academics emphasize factors on peasants themselves such as human capital [3], economic capital [4] and social capital [5]. Some put emphasis not only on peasants' own factors, but also on the influence that external causes have on their development capability, say, the influence of policy, which was stressed by Xianglin Wang [6]. Gao analyzed on the aspect of income distribution its impact on development capability [7]. Zeng pointed out in her research on peasants' development capability that the object consisted of internal force, external force and comprehensive force. She set up several indicators to measure peasants' development capability in the way of measuring the values of the indicators separately. But what was a defect was that she failed to design a general indicator to evaluate peasants' development capability [8]. Afterwards, some scholars remedied this defect by calculating rural household development capability with a general indicator [8]-[11], which averted the difficulties in measuring peasants' development capability with different values of indicators.

By reviewing the related literatures, some points can be observed as follows.

The establishing of indicators of rural household development capability should consider both internal causes and external causes. Internal causes refer to some factors involving peasants themselves, while external causes refer to political and social factors affecting peasants. Thus, the indicator system in this paper shall be established in three aspects, self development capability, self development awareness and public atmosphere. As for the evaluating method of the indicator system, it can be imitated from methods evaluating local sustainable development capability in literatures. Usual methods, as is shown in the above literature reviews, include improved entropy method, analytic hierarchy process and fuzzy mathematics method, etc. Since the answers of the questionnaire are based on subjective feelings of peasants, the data collected accordingly are, to some extent, fuzzy and subjective, which will affect the accuracy of the results. To avoid possible errors in this respect, fuzzy mathematics shall be a practical methodology.

In the unique background of poverty alleviation migration policy in Ningxia, this paper furthered studies in capability poverty by measuring rural household development capability before and after migration with fuzzy mathematics - a method which could hardly be found in former analogous studies. Therefore, based on Sen's capabil-

\footnotetext{
${ }^{1}$ It was released by UNDP.

${ }^{2} 1$ December 2012, it was released on portal website of Central Government.
} 
ity approach, this paper not only evaluated the impacts migration had on peasants' development capability, but also added to the depth and width of the indicator system in measuring rural household development capability. By figuring potential problems in the migrating procedure, this paper offered pragmatic solutions to these problems.

\section{Study area and Methodology}

\subsection{Indicator System of Rural Household Development Capability}

\subsubsection{Concept of Rural Household Development Capability}

The concept of rural household development capability is derived from the concept of peasants' development capability. Ye equated development and changing. In his opinion, peasants' development capability stands for peasants' capabilities that enable them to change their household and rural community through various activities. Zeng considered peasants' development capability as abilities to improve their production and living condition by taking advantage of their environmental and possessed resources. Owing to the inseparability of rural household, the concept was extended to rural household development capability. Qiao defined rural household development capability as peasants' abilities to obtain information and make decisions with their cultivated qualities under market economy, put them into actions, and by which can they improve their self abilities, family strength and living standard. On the ground of Qiao's study, Wang described her view of rural household development capability, a concept stressed more on the motives of peasants' development, from the aspect of endogenous growth. She thought it refer to peasants' ability to make decisions with the space and opportunities in hand for the purpose of acquiring more economic benefits. This definition is also used by Li and Chen [12].

The aforementioned definitions emphasize too much on peasants' initiative and ignore the effect of external factors. One should know that rural household development capability is affected by external factors, such as policy, rural community atmosphere and location, as well as internal ones. As far as the authors concerned, rural household development capabilities represent peasants' abilities to expand their choice by using their possessed resources and external advantages. With these capabilities, family members can improve their health condition, expand their choices of jobs, acquire higher level of education, participate in decision-making of local communities and enjoy public service and social security. As is mentioned above, rural household development capability can be sorted into self development capability, self development awareness and public atmosphere.

\subsubsection{Constructing Indicator System of Rural Household Development Capability}

Peasants in poverty-ridden areas are more restricted than those in other rural areas in three dimensions, development capability, development awareness and development space. Considering former researches on peasants' development capability and the practice in this new era of China's poverty alleviation, the authors try to construct an indicator system of rural household development capability so as to measure capability level. In this system, as can be seen in Table 1, rural household development capability is set up to be the general indicator, followed by 3 first-class indicators, self development capability, self development awareness and public atmosphere. Under the first-class indicators are 21 second-class indicators consist of 57 specific third-class indicators.

1) Self development capability

Peasants' self development capability-peasant makes use of resources to expand his choice of freedom to improve living condition. It is constituted by 8 indicators.

2) Self development awareness

This concept refers to peasant's attitude towards getting rid of poverty and toward life. If a peasant has a strong awareness of self development, in order to cast off poverty, he will be positive about taking part in poverty alleviating programs to improve his development capability and change his obsolete lifestyle. He will plan and pursuit more in future life and redesign his ambition. Under participative poverty alleviation pattern, peasants improve their economic and living condition by social participation and program participation. Peasants' attitude towards matters implies, to some extent, their motives to pursuit a better life. Self development awareness also consists of 8 indicators.

3) Public atmosphere

The third dimension of rural household development capability is public atmosphere. The above two dimensions are both internal factors. In addition, external factors should influence rural household development capability as well. In this paper, public atmosphere is adopted as a set of external factors. It refers to the moral atmosphere and administrative function in villages. It is constituted by 5 indicators. 
Table 1. Indicator system of rural household development capability.

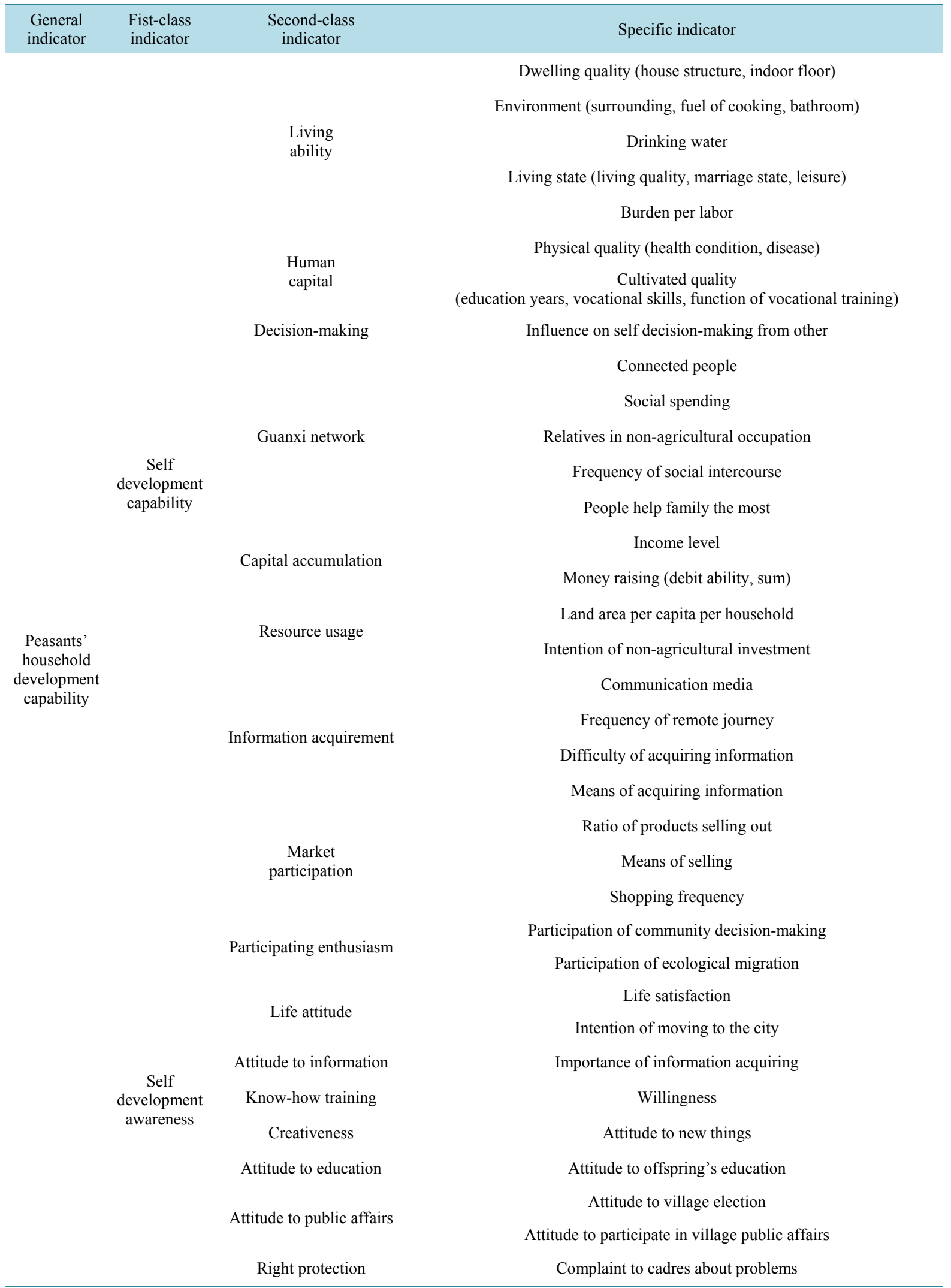




\section{Continued}

\begin{tabular}{|c|c|c|}
\hline & & Relationship between peasants \\
\hline & Social morality & Public order \\
\hline & & Whether or not trust others \\
\hline & & Whether or not trust cadres \\
\hline & & Relationship between cadres and the masses \\
\hline & & Whether or not in election \\
\hline \multirow[t]{7}{*}{ Public atmosphere } & Public participation & Whether or not run for election \\
\hline & & Whether or not in public activities often \\
\hline & tor fono & Satisfaction of openness \\
\hline & Juar antec or transparciticy & Whether or not make public timely \\
\hline & & Whether or not in medical insurance \\
\hline & Social security & Whether or not in subsistence allowance system \\
\hline & & Whether or not in endowment insurance system \\
\hline
\end{tabular}

\subsection{Evaluation Method}

\subsubsection{Samples and Data}

The samples in this research are collected in Liupanshan poverty-ridden areas in Ningxia, and consist of peasants from montanic areas and resettlement areas. The investigation chose 5 counties and districts with a total of 303 observations in montanic areas, Haiyuan (119 households), Jingyuan (58 households), Xiji (70 households), Yuanzhou (33 households) and Tongxin (20 households), to study peasants' development capability. While in resettlement areas, several large resettlement districts with 273 observations were chosen. The districts include Yangxian Village in Shengli Town of Yongning County (15 households), Yuanlong Village in Minning Town (87 households), Binghe Village in Yueyahu Town of Xingqing District (60 households), Heshun Village in Liangtian Town of Jinfeng District (64 households) and Tongyang New Village in Zhenbeipu Town of Xixia District (47 households).

\subsubsection{Fuzzy Mathematic Evaluation}

The requirement of applying fuzzy mathematic evaluation is that the indicators should not be redundant. Otherwise, the undersized weighs of indicators will reduce the distinction of evaluation [13]. Since the indicator system of this paper contains 57 specific indicators, to avoid this problem, the authors will evaluate indicators by class. First of all, the first-class indicators include self development capability, self development awareness and public atmosphere will be evaluated and summed up by their scales. The calculations of first-class indicators are as following steps:

Firstly, fuzzy functions configuring.

The fuzzy function is set as $Z^{m}=\left\{y, v_{m}(y)\right\}, y \in Y . v_{m}(y)$ represents for the membership of $y$ to $Z$, $v_{m}(y) \in(0,1)$. The situation tops when membership is the highest and bottoms when it is the lowest, while the situation will be fuzzy when membership is at median. Moreover, the situation improves as degree of membership grows higher.

Secondly, membership functions configuring.

The memberships function of dummy dichotomous variables:

$$
v\left(y_{i j}\right)= \begin{cases}0, & y_{i j}=0 ; \\ 1, & y_{i j}=1 .\end{cases}
$$

Therein, $y_{i j}$ is the value of the $j$ th indicator of peasant household $i$.

The memberships function of positive continuous variables: 


$$
v\left(y_{i j}\right)= \begin{cases}0, & 0 \leq y_{i j} \leq c ; \\ \frac{y_{i j}-c}{d-c}, & c<y_{i j}<d ; \\ 1, & y_{i j} \geq d .\end{cases}
$$

The memberships function of negative continuous variables:

$$
v\left(y_{i j}\right)= \begin{cases}0, & 0 \leq y_{i j} \leq c ; \\ \frac{d-y_{i j}}{d-c}, & c<y_{i j}<d ; \\ 1, & y_{i j} \geq d .\end{cases}
$$

The continuous variables referred to in this paper contain per capita income, area of cultivated land per capita, daily wage of major labor, social spending and education years. When calculating memberships, given the practical situation, different indicators are bound to different upper and lower limits. The lower limit of per capita income is $¥ 2300$ (new criterion of poverty alleviation), and its median is the average value of the samples. The lower limit of social spending is $¥ 500$, while its upper limit is $¥ 10,000$. The lower limit of area of cultivated land per capita, as is stipulated as the warning line by FAO, is $0.8 \mathrm{mu}$ per capita, and its upper limit applied is the national average area of cultivated land. The lower limit of daily wage of major labor is $¥ 50$, and upper limit $¥ 200$. The lower limit of education years is 6, while the upper limit 13 .

The memberships function of dummy qualitative variables:

$$
v\left(y_{i j}\right)= \begin{cases}0, & 0 \leq y_{i j} \leq c ; \\ \frac{y_{i j}-c}{d-c}, & c<y_{i j}<d ; \\ 1, & y_{i j} \geq d .\end{cases}
$$

Weights of indicators are determined by their practical importance. According to literatures, there are a few ways of weighting. One way is to configure weighting formula based on the principle that the importance of indicator grows as the membership reduces [14]:

$$
\begin{gathered}
q_{j}=\ln \left[\frac{1}{\overline{v\left(y_{j}\right)}}\right] \\
p_{j}=\frac{q_{j}}{\sum_{j=1}^{t} q_{j}}
\end{gathered}
$$

This methodology is also applied in evaluating peasants' welfare in land expropriation [15] [16]. However, the result of evaluation will be lower owing to the emphasis on the importance of indicators with lower membership in general estimation. Thus, in order to maintain the importance of indicators with larger difference, this paper weights indicators in evaluation with standard deviation method. The formula is as follow:

$$
p_{j}=\frac{\sigma_{j}}{\sum_{j=1}^{t} \sigma_{j}}
$$

Therein, $\sigma_{j}$ is the standard deviation of the $j$ th indicator's membership.

Thirdly, the general indicator value is evaluated according to indicators' membership and weight. Here is the function:

$$
Y=\sum_{j=1}^{t} \overline{v\left(y_{i j}\right)} * p_{j}
$$


Following the steps above, the first-class indicators are evaluated. The last step is to total up by their scales,

$$
C=Y_{1} \cdot \frac{33}{57}+Y_{2} \cdot \frac{11}{57}+Y_{3} \cdot \frac{13}{57}
$$

Therein, $C$ represents general rural household development capability (57 specific indicators), $Y_{1}$ is self development capability (33 specific indicators), $Y_{2}$ stands for self development awareness (11 specific indicators), and $Y_{3}$ is public atmosphere (13 specific indicators).

\section{Results Analysis}

\subsection{Analysis of Rural Household Development Capability}

The results are shown in Figure 1. The value of rural household development capability in montanic areas is 0.5205 , lower than that of resettlement areas, 0.5491. This reflects that migration has indeed improved rural household development capability. With regard to subitems, self development capability improves greater than self development awareness and public atmosphere. As peasants moving from montanic areas into resettlement areas, their lifestyle and ways of production have changed greatly, which provide more developing opportunities to peasants in resettlement areas and promote their self development capability. For instance, migration has altered peasants' choice of working. In montanic areas, peasants sustain themselves on primary industry, especially farming and husbandry. For most peasants, farming is far more important than any other work. Only when in slack season or there are spare labors would they choose to go out for part-time jobs. However, the ecological environment of middle and south areas of Ningxia is too barren to develop farming, so the peasants are confined to low income. On the other hand, migration has deprived peasants of their lands. They can no longer stand on farming. Peasants have to initiatively go out for job with higher income compared to farming to sustain their family. This alteration drives peasants to improve their working skills to seek for higher income. Moreover, the living conditions are also improved in resettlement areas, say, drinking water, fuel of cooking and communication, etc.

As is shown in results, peasants' self development awareness has increased. Self development awareness reflects peasants' awareness or willingness to improve their development capability, which requires the stimulation of external forces. In montanic areas, peasants live in a self-sustainable farming pattern. This seemingly obsolete lifestyle reduces peasants' willingness to improve or strengthen their capability, and satisfies themselves easily. Luckily, this pattern is damaged by migration. Life in new environment urges them to seek for new survival mode as well as new plans and goals for life. It also stimulates their awareness of self development.

Public atmosphere shows only a slight increase after migration. This first-class indicator consists of external factors, mainly policy guarantee and life safeguard such as franchise, medical devices and old-age pensions. It is

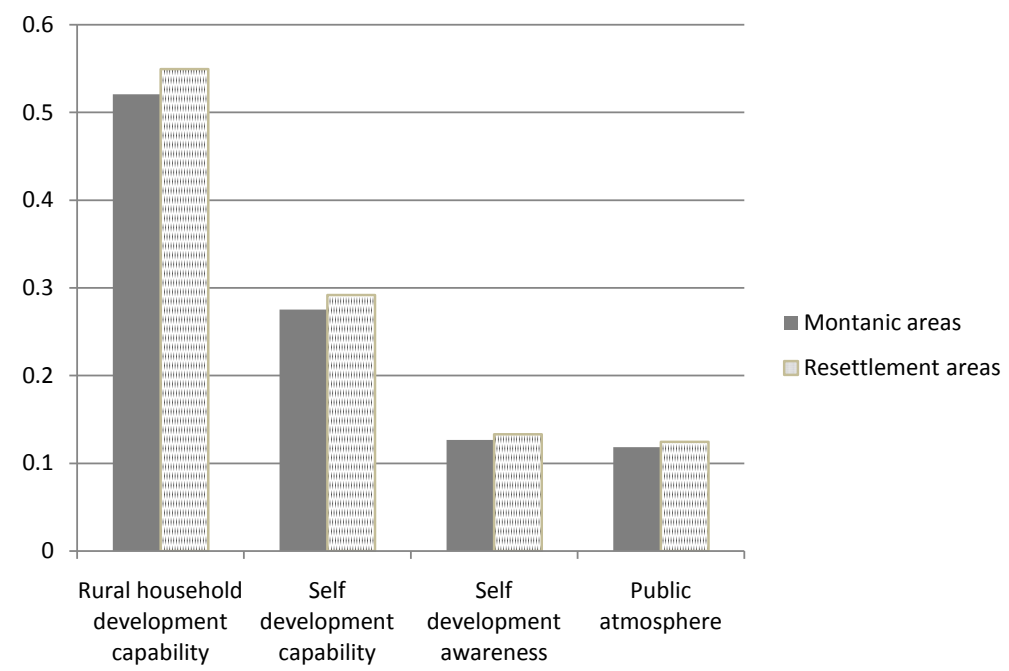

Figure 1. Comparison of general value and three indicators. 
merely a matter of policy tendency of government. Government's certain tendency increases the impact of certain indicators. That is why it is barely influenced by migration.

\subsection{Analysis of Self Development Capability}

From Figure 2, it can be seen that, after migration, every other indicators are increased except for capital accumulation ability, market participation ability and guanxi network. Among the increased indicators, living ability, human capital and information acquiring ability increase most remarkably, which reflects that migration improved peasants' self development capability, the three indicators in particular. The indicator living ability includes dwelling quality, life quality, living condition, burden per labor and drinking water, etc. Migration has changed peasants' house structure from earth house and brick-wood house to reinforced concrete house. The houses are of stronger structure but smaller area. Besides, the resettlement districts have constructed recycling stations, and the fuels of cooking are mainly electricity and gas. Thus, the sanitation of environment is much better than that of montanic areas. The communication is improved by placing resettlement villages in places of better traffic and nearer to metropolises. A notable disadvantage of poverty-ridden areas in Ningxia is their lack of water. Peasants in a few villages sustain their life even with open water. This is all solved in resettlement villages. These villages supply peasants with running water; bad water quality and lack of water have been put to an end in their entirety. Though there is complaint from some peasants that the water supply is occasionally cut off, their basic water usage has been guaranteed. In general, peasants' living abilities have been improved because migration has promoted their living conditions in a few aspects.

Peasants' human capital is also increased after migration. It is mostly reflected by improvements in their cultivated qualities. After migration, a vast majority of peasants in resettlement villages take part in know-how training (while similar training is held in few villages in montanic areas). Among the 273 households investigated, about $45.42 \%$ of peasants acquired analogous training, of which $49.2 \%$ have applied these newly learnt skills. On the contrary, in montanic areas, only $22 \%$ of peasants have participated in know-how training. Know-how training can improve and reinforce one's ability in certain fields and increase its return in the form of more income. It sure will improve peasants' economic condition and life quality. Thus, know-how training is of great importance to both resettlement areas and montanic areas.

Peasants' ability of information obtainment has improved remarkably after migration. This ability is closely related to ways of communication and information obtaining media. Peasants get access to the Internet in resettlement areas apart from their cell phones. Along with economic developing, information grows more and more important. As the most popular medium of information, the Internet has also a growing importance. In resettlement areas, $5 \%$ of households use the Internet to obtain information, while no network is available in montanic areas. Therefore, the spread of communication devices improves peasants' ability of obtaining information.

Guanxi network, a crucial social resource, accumulates to benefit peasants in economic ways. Peasants in re-

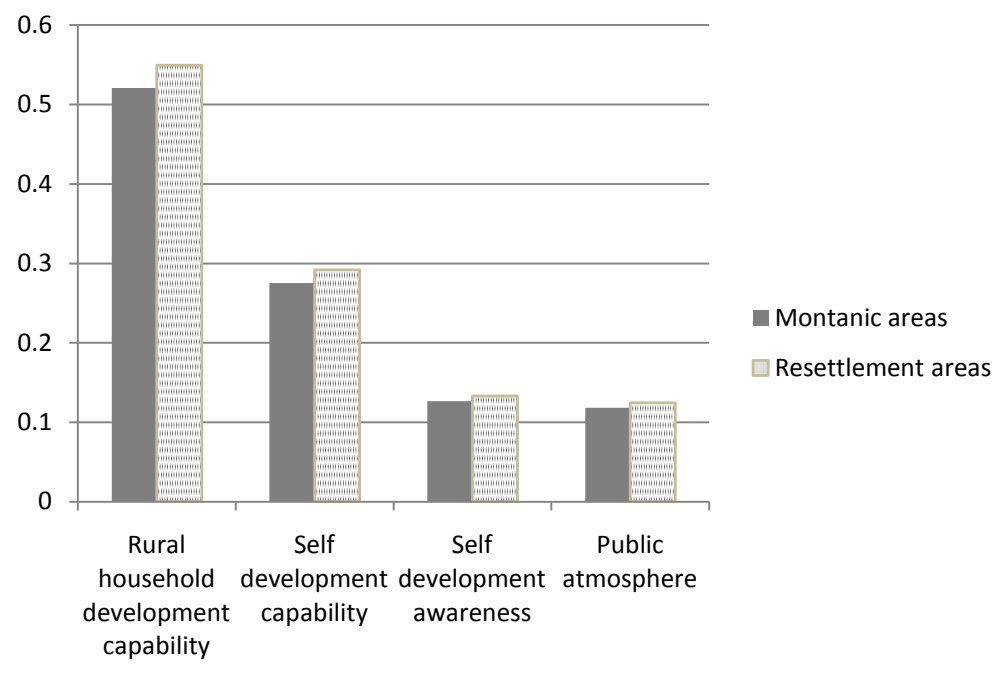

Figure 2. Self development capability. 
settlement areas have a lower value of this indicator because their social connections and spending have become fewer, and so have the number of people who help them most. Peasants in resettlement villages are from different areas in montanic areas with awfully different custom and culture, which have, to some extent, hindered their fusion. It is an urgent business to rebuild their guanxi network.

Capital accumulation ability increases along with the growth of one's economic strength. After migration, for certain reasons, peasants' economic strength and borrowing capacity reduce as their income goes down. Their ability of capital accumulation therewith has reduced. As a result, peasants have lost former financial support to improve their present economic condition and to get rid of poverty. Thus, it is of great value to improve peasants' ability of capital accumulation.

Fuzzy mathematics method weights indicators in accordance with the standard deviation of their membership. The higher the standard deviation, the greater is the weight of indicator. Market participation ability consists of three indicators, ratio of products selling out, means of selling and shopping frequency. Peasants' lands have decreased in a large amount in the process of migrating, and their scarce land has been jointly contracted. Hence, the values of ratio of products selling out and means of selling shall be reduced, and so do their membership. The values of these two indicators differ greatly in montanic areas and resettlement areas, so they are of great weight. The combination of lower membership and greater weight may reduce the value of indicators. In addition, the standard deviation of shopping frequency in resettlement areas is larger than that of montanic areas, which shows a greater difference of this indicator among peasants in resettlement villages, and it should be given greater weight. The reduction of shopping frequency also reflects a lower membership of the indicator.

\subsection{Analysis of Self Development Awareness}

As is shown in Figure 3, all indicators except for life attitude increase to various extents. Life attitude is constituted of two indicators, life satisfaction and intension of moving to the city. In measuring with standard deviations, it can be discovered that the deviation of life satisfaction of resettlement areas is greater than that of montanic areas. Thus, this indicator weights more in resettlement areas than in montanic areas. Moreover, the membership of this indicator reduces after migration, which also dwindle the value of life attitude.

Apart from life attitude, the other seven indicators in self development awareness improve more or less after migration. This shows an increase in self development awareness. Indicators improve the most include awareness of right protection, attitude to training, to creativeness and to information. After migration, peasants' life style, regardless of ways for living or environment, has changed which brings new hopes for life and yearning for city. On the drive of this strong will, peasants struggle to improve their development capability for a better life. Peasants in resettlement areas are more initiative in participating in public affairs than those in montanic areas. The reason is that new ways of management in resettlement areas alter peasants' attitude towards public affairs, and hasten their willingness to take part in it. Skills and information are made more influential to peasants, under the circumstance that migrating for work has predominated in living, so that they can find jobs with better income

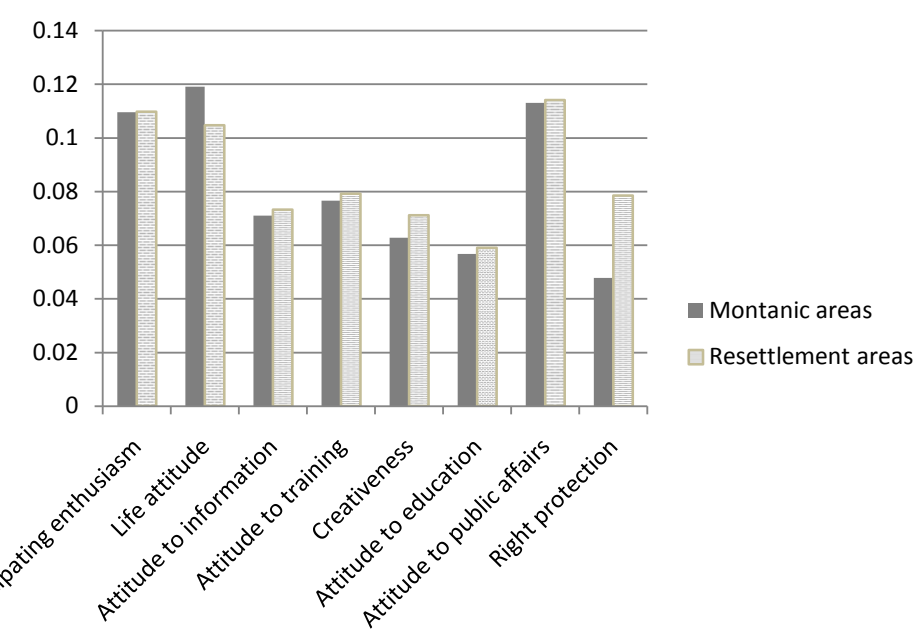

Figure 3. Self development awareness. 
by improving working skills and obtain information on occupation and money making. Thus, their wishes to acquire know-how training grow intensively after migration. On the contrary, for most peasants in montanic areas, they are not in need of much expertise since they only go for part-time jobs in slack seasons.

\subsection{Analysis of Public Atmosphere}

In Figure 4, the results show a growth in the value of every indicator except for social morality. Compared to other indicators, public participation, guarantee of transparency and cadre-masses relationship improve greater in migrating, and social security does not change much.

The value of indicator public participation is increased by constantly held public activities, such as artistic plays and books' country-distribution by the government. Similar activities have enriched peasants' daily life. Guarantee of transparency has satisfied peasants' demand for transparency. Openness of information can not only prevent corruption and financial malpractice, but also provide a certain degree of fairness for peasants. As a contrast, $43.59 \%$ of households in resettlement areas are satisfied with the openness of village management, while only $34.44 \%$ in montanic areas feel the same. Peasants in resettlement areas are more capable of obtaining management information. Thus, it can be inferred that guarantee of transparency in resettlement areas is better than in montanic areas. In addition, cadre-masses relationship is also improved. It is owing to the new methods of village management, more reasonable and transparent methods, that the cadres and the peasants are able to develop a much more harmonious relationship. In terms of indicator social security, it is more or less the same in resettlement areas as is in montanic areas since the policies of old-age pensions and health care remain the same in the process. The value of the participation of endowment insurance is a bit lower in montanic areas, and ratios of participators of medical insurance and subsistence allowance remain unaltered.

The indicator social morality reduces greatly in migration, which shows a sharp reduction in the trust among peasants. Peasants have experienced unpleasant relationships and a disturbing community security in village. The whole unfamiliar environment, total difference in custom and culture and bad community security are combined to result in intense distrust in peasants' relationship. The reduction in social morality may prevent peasants from settling down, and stimulate their eagerness to move back to poverty-ridden areas. Hence, we should realize this problem and take actions fast to create a better mood so as to promote harmony in community.

\section{Conclusions}

\subsection{Improving of Rural Household Development Capability and Outstanding Effectiveness of Policy}

By comparing the results of the two areas, the authors find that the value of rural household development capability in resettlement areas is higher than that in montanic areas. This reflects that migration has indeed improved rural household development capability and thereby helped them casting off poverty. The improvement in the object also shows the outstanding effectiveness of this migration program. It is worthy of acknowledgement and wide adoption.

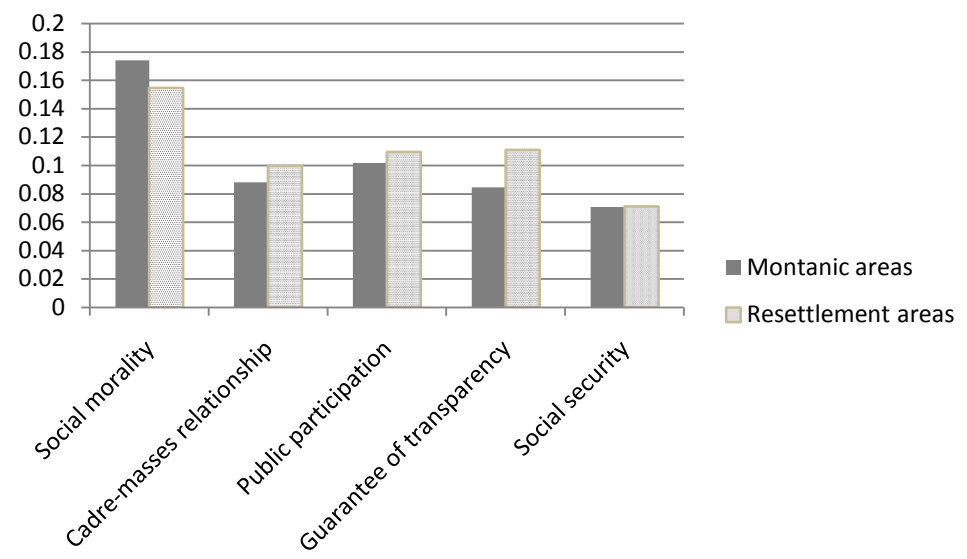

Figure 4. Public atmosphere. 
1) Improvements in self development capability

It is mostly affirmed by the improvements in facilities, for example, communication between peasants and the city, improvement in dwelling structure, more convenience in water usage, better environmental sanitation, more construction of schools, more offers of know-how training, better decision-making ability and better media of market participation.

2) Improvements in self development awareness

After migration, peasants add more importance on children's education, information acquiring and know-how training, and they are more initiative. These improvements provide great boost for peasants' future development. Education and training improve peasants' quality; initiative widens ways of making money, and information provide chances for more wealth and better occupation.

3) Improvements in public atmosphere

Improvements in public atmosphere are reflected mainly in better cadre-masses relationship, more frequent of public activities and better guarantee of transparency. Cadre-masses relationship shows better ability of cadres to serve the masses. Holding of public activities promotes peasants' life quality. The strengthening of transparency, realized by more openness in village management, will prevent corruption.

\subsection{Downgoing Indicators of Rural Household Development Capability}

Peasants' per capita income decreases owing to lessening sources of income. In montanic areas, peasants can sustain themselves by both wages and family operational income, while only daily wages are available to them in resettlement areas. In addition to reduction of per capita income, the negative influences that migration has brought on peasants' self development capability include decreasing in areas of dwelling, impairment of old guanxi network and lack of media of money raising, etc. All these negative influences have injured peasants' subjective perception on life in resettlement areas. Up to $27 \%$ of peasants sense deterioration in living condition. What's more, migration has cast shadow on peasants' self development awareness and public atmosphere as well. The indicators affected in the former are reduction in life satisfaction, ignorance of the right to vote and initiative to participate in community decision-making. As for the latter, the impacts lie in the worsening of social morality and the deprivation of opportunities for voting.

\subsection{Future Research Direction}

This paper studies poverty alleviation problem by evaluating rural household development capability, which is based mainly on Sen's capability approach. However, the approach can only assess the effect of poverty alleviation policy on peasants' material conditions. What really matters is how these policies are designed to improve peasants' happiness. Thus, future studies of the authors will chiefly focus on what the ecological migration will do to peasants' subjective well-being.

\section{References}

[1] Sen, A. (2002) Development as Freedom. China Renmin University Press, Beijing.

[2] Sen, A. (2007) The Standard of Living. Shanghai University of Finance and Economics Press, Shanghai.

[3] Chen, L. (2005) Research on Capability of Landless Peasants. Ph.D. Thesis, Chinese Academy of Social Science, Beijing.

[4] Qian, Z.H. and Xu, M.Y. (2008) Research on the Loss and Reconstruction of Landless Peasants' Capability in China. Academic Research, 12, 69-74.

[5] Wang, X.L. (2010) Peasants' Development Capability: Internal Drive of Rural Development. Journal of Guangxi University, 5, 61-65.

[6] Ye, J.Z. (2004) Creating Space for Change. China Rural Survey, 4, 37-46.

[7] Gao, Y. (2011) Income Distribution: Economic Growth or Human Development. Contemporary Finance \& Economics, 10, 26-34.

[8] Zeng, Y.H. (2006) Issues and Countermeasures on Peasants' Development Capability. Reformation Strategy, 2 , 29-33.

[9] Wang, L. (2008) Rural Households' Viability: Empirical Analysis on Rural Households' Income Endogenous Growth. Ph.D. Thesis, Henan University, Henan.

[10] Qiao, J.J., Zhao, D.H. and Li, X.J. (2008) A Comparative Study on Rural Households' Viability. System Sciences and 
Comprehensive Studies in Agriculture, 3, 351-354.

[11] Li, X.J., Qiao, J.J., Zhou, X.F., Wang, L. and Wang, Y.C. (2009) Self-Developing Ability of Rural Households and Its Impact on Growth of the Household Income: A Geographical Study. Acta Geographica Sinica, 6, 643-653.

[12] Li, J. and Chen, C.Y. (2013) Analysis of the Influence of Regional Environment on the Development Capability of Peasants in Poverty. Rural Economy, 6, 72-75.

[13] Zhang, M.Z. (1997) Fuzzy Mathematics and Martial Decisions. National Defense University Press, Beijing.

[14] Cheli, B. and Lemmi, A. (1995) A "Totally" Fuzzy and Relative Approach to the Multidimensional Analysis of Poverty. Economic Notes, 24, 115-133.

[15] Gao, J.Y., Qiao, R.F. and Zhang, A.L. (2007) Fuzzy Estimation of Peasants' Welfare before and after Land Expropriation Based on Sen's Capability Approach. Management World, 6, 45-53.

[16] Xu, F.F., Li, F. and Tang, Y. (2010) Fuzzy Estimation of Peasants Welfare before and after the Replacement of Contract and Management Right of Land in South Jiangsu. Chinese Rural Economy, 8, 67-79. 